\title{
Antibody responses to porcine reproductive and respiratory syndrome virus, influenza A virus, and Mycoplasma hyopneumoniae from weaning to the end of the finisher stage in fourteen groups of pigs in Ontario, Canada
}

\author{
Elana Raaphorst ${ }^{1}$, Abdolvahab Farzan ${ }^{1,2^{*}}$ (D), Robert M. Friendship ${ }^{2}$ and Brandon N. Lillie
}

\begin{abstract}
Background: Respiratory diseases are among the most important factors affecting swine farm productivity in Canada. The objectives of this study were to investigate antibody responses to porcine reproductive and respiratory syndrome virus (PRRSV), influenza A virus (IAV), and Mycoplasma hyopneumoniae (M. hyopneumoniae) from weaning to the end of the finisher stage on a subset of commercial swine farms in Ontario, Canada, and to examine the association between nursery diet and antibody responses.

Results: Overall, older pigs were more likely to test seropositive for PRRSV and less likely to test seropositive for $M$. hyopneumoniae $(p<0.001)$. Pigs were more likely to test seropositive for IAV at weaning and the end of the grower and finisher stages compared to the end of nursery $(p<0.001)$. Pigs that were seropositive for IAV were more likely to test seropositive for both PRRSV and M. hyopneumoniae $(p<0.001)$. Two, 9, and 4 groups that had more than $20 \%$ of pigs seropositive to PRRSV, IAV, and M. hyopneumoniae, respectively, from the end of nursery to the end of finisher were classified as seropositive. Pigs fed a plant-based (low complexity) diet during nursery were more likely to be seropositive for PRRSV $(p<0.001)$ but there were no significant differences in seropositivity to IAV or M. hyopneumoniae due to nursery diet complexity.

Conclusions: This study provides information regarding changes in serum antibody in pigs across different stages of production and highlights periods of vulnerability. Additionally, these findings may encourage further research into the effects of nursery diet complexity on disease susceptibility and immune response.
\end{abstract}

Keywords: Porcine reproductive and respiratory syndrome, Influenza A virus, Mycoplasma hyopneumoniae, ELISA, Antibody response, Nursery diet, swine

\footnotetext{
* Correspondence: afarzan@uoguelph.ca

1 Department of Pathobiology, University of Guelph, 50 Stone Road East, Guelph, ON N1G 2W1, Canada

${ }^{2}$ Department of Population Medicine, University of Guelph, 50 Stone Rd E,

Guelph, ON N1G 2W1, Canada
}

(c) The Author(s). 2021 Open Access This article is licensed under a Creative Commons Attribution 4.0 International License, which permits use, sharing, adaptation, distribution and reproduction in any medium or format, as long as you give appropriate credit to the original author(s) and the source, provide a link to the Creative Commons licence, and indicate if changes were made. The images or other third party material in this article are included in the article's Creative Commons licence, unless indicated otherwise in a credit line to the material. If material is not included in the article's Creative Commons licence and your intended use is not permitted by statutory regulation or exceeds the permitted use, you will need to obtain permission directly from the copyright holder. To view a copy of this licence, visit http://creativecommons.org/licenses/by/4.0/. The Creative Commons Public Domain Dedication waiver (http://creativecommons.org/publicdomain/zero/1.0/) applies to the data made available in this article, unless otherwise stated in a credit line to the data. 


\section{Background}

Respiratory diseases are important factors affecting swine farm productivity and animal health and welfare. Respiratory diseases may impair growth rates, contributing to poorer quality meat products, and can increase the need for drug use and the costs associated with swine production $[1,2]$. Porcine reproductive and respiratory syndrome virus (PRRSV), influenza A virus (IAV), and Mycoplasma hyopneumoniae (M. hyopneumoniae) are three of the most significant pathogens affecting swine farm productivity [3]. Despite efforts to eradicate these pathogens and their associated diseases, they continue to be widespread in the world swine population and result in huge economic losses for pork producers. These infectious agents can be detrimental to production on their own, and the presence of multiple infectious agents on-farm can increase the risk for coinfection [4-7] and can also lead to more severe disease than single infection with either agent(s) $[8,9]$. These interactions may further exacerbate declines in producer profits and animal welfare [1].

The developing immunity of young pigs can also increase the difficulty in preventing disease on farm. As piglets are weaned from the dam, their levels of maternal antibodies decline, after which pigs begin to produce their own antibodies as they become exposed to pathogens and their immune systems start to develop [10]. This decrease in maternal antibody levels increases the risk for disease in young pigs. While vaccination is a common practice on swine farms, the prevalence of particular pathogens in a herd may change due to many factors including but not limited to proximity to other herds, air quality, biosecurity, genetics, in-feed medication, as well as diet and feeding program [11-14].

Pigs commonly receive a series of starter feeds in order to slowly transition weanlings from expensive, complex diets containing easily digestible ingredients such as milk products and fishmeal to less expensive diets consisting of simpler, plant-based ingredients [15]. This allows pigs to develop the necessary enzymes required for digesting the constituents found in adult diets and reduces postweaning growth lag $[15,16]$. Proper feeding also improves resistance to many bacterial and parasitic infections and shortens recovery times. However, not only is feed the costliest aspect associated with pork production, but nursery diet costs are especially high due to the need for a highly palatable feed that will allow the immature gut of the pig to adapt from an easily digestible milk diet to solid, grain-based feed [16]. Substituting complex proteins in nursery feed for simpler, plant-based proteins may offer cost-saving benefits to producers without sacrificing carcass quality and growth rate [17].

However, humoral and inflammatory responses may be reduced in pigs receiving diets containing higher levels of soy protein which could indicate immune function is compromised due to this type of diet [18]. While previous research has demonstrated that low complexity nursery diets have no significant effect on antibody responses to Salmonella [19], further research is still needed in order to better understand the possible effects of nursery diet complexity on antibody responses to other important porcine production-limiting pathogens.

The objectives of this study were: 1) to measure antibody responses to PRRSV, IAV, and M. hyopneumoniae in pigs from weaning to the end of the finisher stage; 2) to examine the relationship in antibody responses among those three pathogens; and 3) to determine the association of a nursery diet that uses mostly plant protein (compared to the typical complex animal proteinbased diet) with seropositivity to PRRSV, IAV, and $M$. hyopneumoniae.

\section{Results}

Seropositivity to PRRSV, IAV, and M. hyopneumoniae at the pig and group level

Of the 336 pigs tested for all three pathogens at four visits, 24 (7.1\%) were seronegative for all three pathogens throughout production, 165 (49.1\%) were seropositive for one at least once over the course of production, 124 (36.9\%) were seropositive for two, and 23 (6.9\%) were seropositive for all three pathogens.

Figure 1 displays the percentage of pigs that were seropositive for each pathogen from the end of nursery to the end of the finisher stage. Due to the possible confounding effects of passive immunity on the objectives of this study, groups were considered positive for each pathogen if more than $20 \%$ of pigs in that group tested seropositive for that pathogen at least once from the end of nursery to the end of the finisher stage. The proportion of seropositivity to each pathogen in pigs fed high or low complexity diet in seropositive groups is shown in Fig. 2. Of the 14 groups, two were classified as seropositive for PRRSV (pig seropositivity: 38.3-65.0\%), nine groups were seropositive for IAV (pig seropositivity: 33.3-70.0\%), and four were seropositive for M. hyopneumoniae (pig seropositivity: 26.7-85.0\%) (Table 1). Statistical analysis was then conducted on the positive groups from weaning to the end of the finisher stage at the pig level in order to determine how seropositivity changes over the course of production.

\section{Multivariable analysis}

PRRSV. Pigs from two seropositive groups that had more than $20 \%$ of pigs test seropositive for PRRSV at least once over the course of production were included in the multivariable analysis. In the two seropositive groups, seropositivity was likely to increase with age $(p<0.001)$. Pigs fed a low complexity nursery diet were 


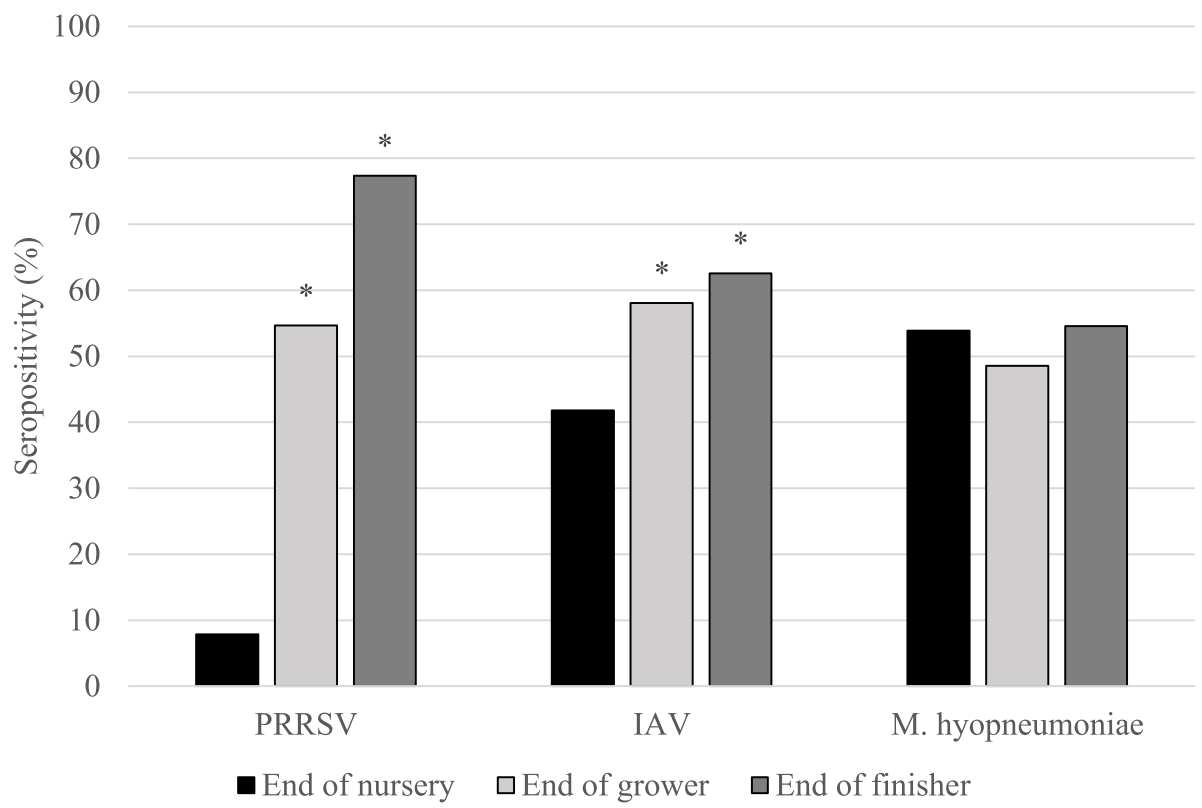

Fig. 1 Percentage of pigs seropositive for PRRSV, IAV, and M. hyopneumoniae from the end of nursery to the end of finisher. This figure depicts the percentage of pigs that were seropositive for porcine reproductive and respiratory syndrome virus (PRRSV), influenza A virus (IAV), and Mycoplasma hyopneumoniae in seropositive groups at each stage of production from the end of nursery to the end of the finisher stage. Note: Two, 9 and 4 groups were classified as seropositive for PRRSV, IAV, and M. hyopneumoniae, respectively. *Significantly different from end of nursery $(p<0.05)$

more likely to be seropositive than those fed a high complexity diet $(\mathrm{p}<0.001)$ (Table 2). The combination of production stages in which pigs were seropositive for PRRSV if tested at four visits is shown in Fig. 3. Four pigs from two different farrowing sources were identified as outliers. The best linear unbiased predictors followed a normal distribution and the model met the homoscedasticity assumption.

Table 1 Pig-level seropositivity to PRRSV, IAV, and $M$. hyopneumoniae in 14 groups of pigs

\begin{tabular}{|c|c|c|c|c|c|c|c|c|c|}
\hline & \multirow[b]{3}{*}{ Cohort } & \multicolumn{8}{|c|}{$\%$ of pigs testing seropositive at least once } \\
\hline & & \multicolumn{8}{|c|}{ Farrowing source } \\
\hline & & 1 & 2 & 3 & 4 & 5 & 6 & 7 & 8 \\
\hline \multirow[t]{2}{*}{ PRRSV } & One & 0.0 & 0.0 & 0.0 & 0.0 & 8.3 & 38.3 & 0.0 & 0.0 \\
\hline & Two & 1.7 & ND & 0.0 & 0.0 & 0.0 & 0.0 & ND & 65.0 \\
\hline \multirow[t]{2}{*}{ IAV } & One & 35.2 & 17.2 & 33.3 & 3.3 & 11.7 & 13.3 & 60.0 & 70.0 \\
\hline & Two & 5.0 & ND & 68.3 & 51.7 & 68.3 & 63.3 & ND & 70.0 \\
\hline \multirow[t]{2}{*}{ M. hyo } & One & ${ }^{\mathrm{a}} 72.2$ & 8.6 & 0.0 & 1.7 & 85.0 & 1.7 & 48.3 & 11.7 \\
\hline & Two & ${ }^{\mathrm{a}} 25.0$ & ND & 1.7 & 0.0 & 66.7 & 1.7 & ND & 26.7 \\
\hline
\end{tabular}

This table depicts the percentage of individual pigs that were seropositive for porcine reproductive and respiratory syndrome virus (PRRSV), influenza A virus (IAV), or Mycoplasma hyopneumoniae at least once in 14 groups of pigs from 8 farrowing sources. A group was considered seropositive if more than $20 \%$ of pigs were seropositive at least once from the end of nursery to the end of the finisher stage

ND No data (blood samples were not collected)

a Vaccinated for M. hyopneumoniae
IAV. Pigs from nine seropositive groups that had more than $20 \%$ of pigs test seropositive for IAV at least once from the end of nursery to the end of finisher were included in the multivariable analysis. Pigs were more likely to be seropositive for IAV at weaning and the end of the grower and finisher stages compared to the end of nursery $(p<0.001)$. Pigs in Cohort Two (born between October and January) were more likely to be seropositive than pigs in Cohort One (born between May and August $)(\mathrm{p}<0.001)($ Table 3$)$. Pigs that were seropositive for $M$. hyopneumoniae were more likely to be seropositive for IAV $(p=0.007)$. There was no significant association between diet and antibody responses $(p=0.17)$. The variation in pig seropositivity due to farrowing source and sow was 78.3 and $21.7 \%$, respectively. The combination of production stages in which pigs were seropositive for IAV if tested at four visits is shown in Fig. 4. Examining the Pearson residual, nine pigs from 3 different farrowing sources were identified as outliers. The best linear unbiased predictors followed a normal distribution and the model met the homoscedasticity assumption.

\section{M. hyopneumoniae}

Six groups had more than $20 \%$ of pigs test seropositive at least once for $M$. hyopneumoniae from the end of nursery to the end of the finisher stage. However, two seropositive groups from one farrowing source were 
Table 2 Mixed-effects multi-level logistic regression analysis for porcine reproductive and respiratory syndrome virus (PRRSV) seropositivity

\begin{tabular}{|c|c|c|c|c|}
\hline Parameter & Odds ratio & Standard error & $95 \%$ confidence interval & $p$-value \\
\hline \multicolumn{5}{|l|}{$\operatorname{Diet}^{a}$} \\
\hline $\mathrm{HC}$ & Referent & & & \\
\hline LC & 10.60 & 3.90 & $5.18-21.90$ & $<0.001$ \\
\hline \multicolumn{5}{|c|}{ IAV seropositivity } \\
\hline No & Referent & & & \\
\hline Yes & 3.03 & 1.3 & $1.3-7.0$ & 0.009 \\
\hline Age (weeks) & 1.26 & 0.04 & $1.18-1.40$ & $<0.001$ \\
\hline
\end{tabular}

This table displays the mixed-effects multi-level logistic regression analysis for porcine reproductive and respiratory syndrome virus (PRRSV) seropositivity with sow as a random effect in 2 seropositive groups from 2 different farrowing sources that had more than 20\% of pigs test seropositive to PRRSV by ELISA IAV influenza $A$ virus

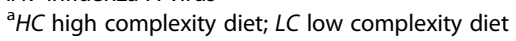

excluded from the multivariable analysis as sows and pigs in those groups were vaccinated for M. hyopneumoniae. Therefore, only pigs from four seropositive groups from three different farrowing sources were included in the multivariable analysis. Within these groups, pigs that were seropositive for IAV $(p<0.001)$ were more likely to be seropositive for M. hyopneumoniae (Table 4). Older pigs were less likely to test seropositive compared to younger pigs $(\mathrm{p}<0.001)$. The farrowing source was associated with seropositivity to $M$. hyopneumoniae $(\mathrm{p}<0.001$ ). There was no significant association between diet and antibody responses to $M$. hyopneumoniae $(p=0.97)$. The combination of production stages in which pigs were seropositive for M. hyopneumoniae if tested at four visits is shown in Fig. 5. Plotting the Pearson residuals against the predictive probability of $M$. hyopneumoniae seropositivity, six pigs from two different farrowing sources were identified as outliers. The best linear unbiased predictors followed a normal distribution and the model met the homoscedasticity assumption.

\section{Discussion}

One objective of this study was to investigate antibody responses to porcine reproductive and respiratory syndrome virus, influenza A virus, and Mycoplasma hyopneumoniae in pigs at different stages of production. In general, seropositivity indicates that an animal has either absorbed maternally derived antibodies or has been exposed to infectious agents through natural infection or vaccination and was able to mount a robust immune response.

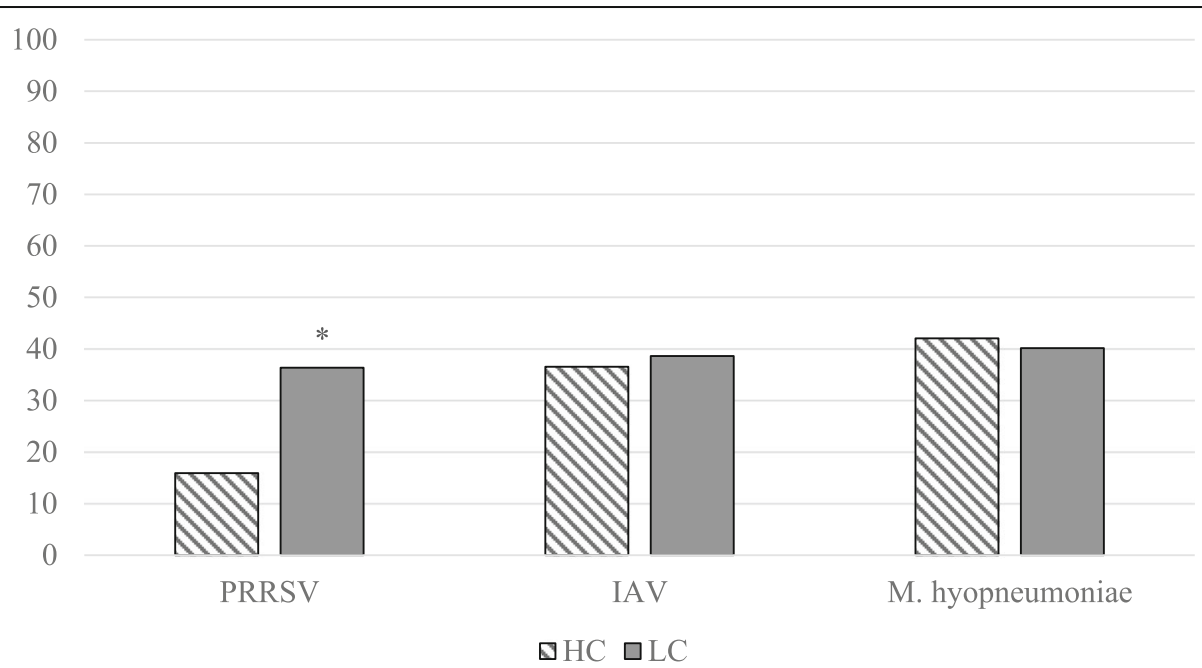

Fig. 2 Combination frequency of pigs that were seropositive for PRRSV at different stages of production. This figure displays pigs that were tested at 4 visits and were seropositive for porcine reproductive and respiratory syndrome virus (PRRSV) at least once throughout production. The data are presented as intersections for each combination of production stages in which pigs were seropositive, with seropositivity represented by dots in the horizontal axis. The number of seropositive pigs per intersection are displayed above the corresponding bar and arranged from the largest intersection to the smallest. Dots are connected by a line if pigs were seropositive at more than 1 production stage. For example, the largest number of pigs were seropositive for PRRSV only at weaning, followed by pigs that were only seropositive at the end of the finisher stage, etc. 
Table 3 Mixed-effects multi-level logistic regression analysis for influenza A virus (IAV) seropositivity

\begin{tabular}{|c|c|c|c|c|}
\hline Parameter & Odds ratio & Standard error & 95\% confidence interval & p-value \\
\hline \multicolumn{5}{|c|}{ M. hyo seropositivity } \\
\hline No & Referent & & & \\
\hline Yes & 1.66 & 0.31 & $1.15-2.41$ & 0.007 \\
\hline \multicolumn{5}{|l|}{ Production stage } \\
\hline At weaning & 3.10 & 0.54 & $2.20-4.35$ & $<0.001$ \\
\hline End of nursery & Referent & & & \\
\hline End of grower & 2.30 & 0.40 & $1.63-3.22$ & $<0.001$ \\
\hline End of finisher & 2.89 & 0.52 & $2.03-4.10$ & $<0.001$ \\
\hline \multicolumn{5}{|l|}{ Cohort $^{\mathrm{a}}$} \\
\hline One & Referent & & & \\
\hline Two & 3.64 & 0.98 & $2.15-6.16$ & $<0.001$ \\
\hline
\end{tabular}

This table displays the mixed-effects multi-level logistic regression analysis for influenza A virus (IAV) seropositivity with farrowing source and sow as random effects in 9 seropositive groups that had more than $20 \%$ of pigs test seropositive to IAV by ELISA

M. hyo = Mycoplasma hyopneumoniae

${ }^{a}$ Cohort One: Pigs were born between May and August; Cohort Two: Pigs were born between October and January

Seropositivity proportions were high at weaning for all three pathogens, likely due to the absorption of antibodies through the sow's colostrum and milk [20, 21], and low again at the end of the nursery stage. Seropositivity was more likely to increase with age for PRRSV and was also more likely to be higher at the end of the grower and finisher stages compared to the end of the nursery stage for
IAV. The decline in seropositivity observed from weaning to the end of nursery in this study indicates the loss of maternal antibodies [10], which also suggests that pigs are particularly susceptible to infection post-weaning. Except for one farrowing source and its two out-going groups, which were vaccinated for M. hyopneumoniae, there was no vaccination to any of the three pathogens in the

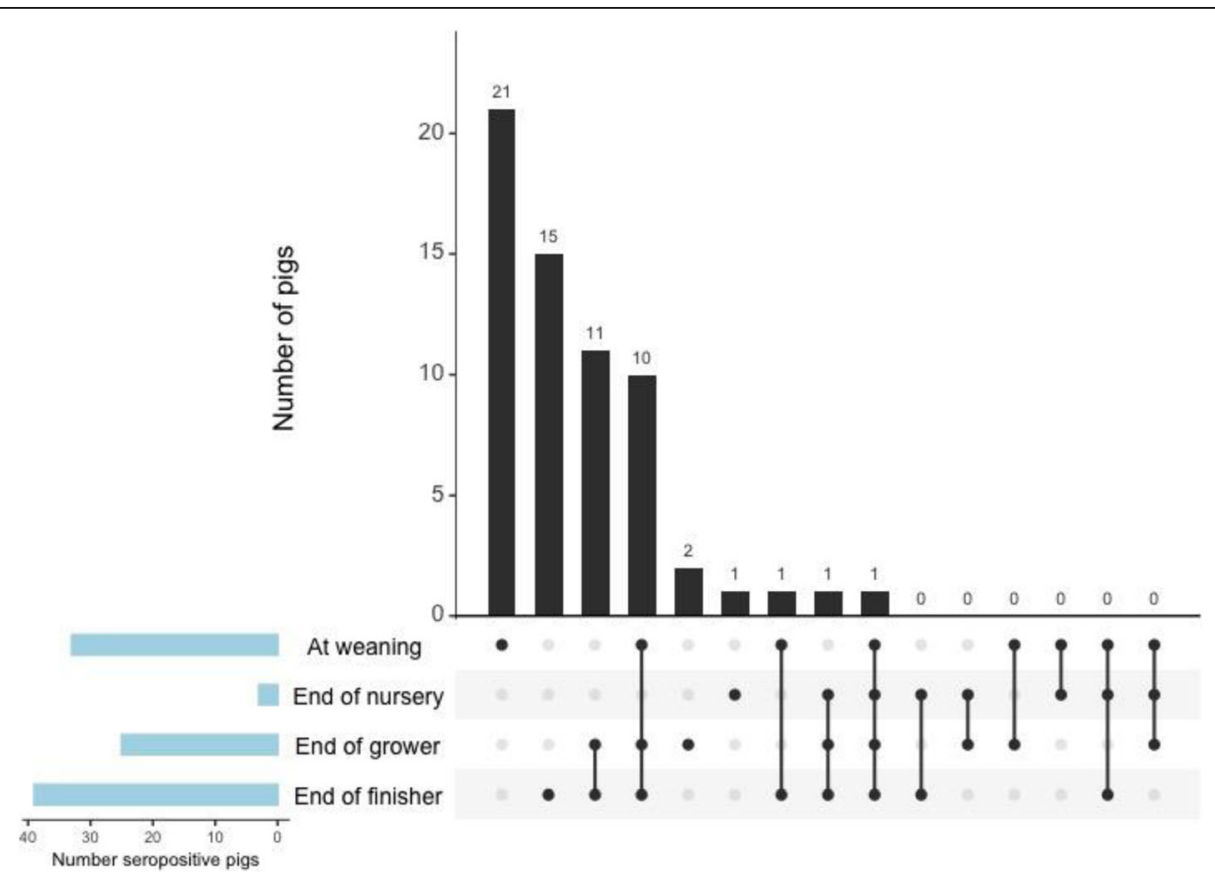

Fig. 3 Combination frequency of pigs that were seropositive for IAV at different stages of production. This figure displays pigs that were tested at 4 visits and were seropositive for influenza A virus (IAV) at least once throughout production. The data are presented as intersections for each combination of production stages in which pigs were seropositive, with seropositivity represented by dots in the horizontal axis. The number of seropositive pigs per intersection are displayed above the corresponding bar and arranged from the largest intersection to the smallest. Dots are connected by a line if pigs were seropositive at more than 1 production stage. For example, the largest number of pigs were seropositive for IAV only at weaning, followed by pigs that were seropositive at all four production stages, etc. 


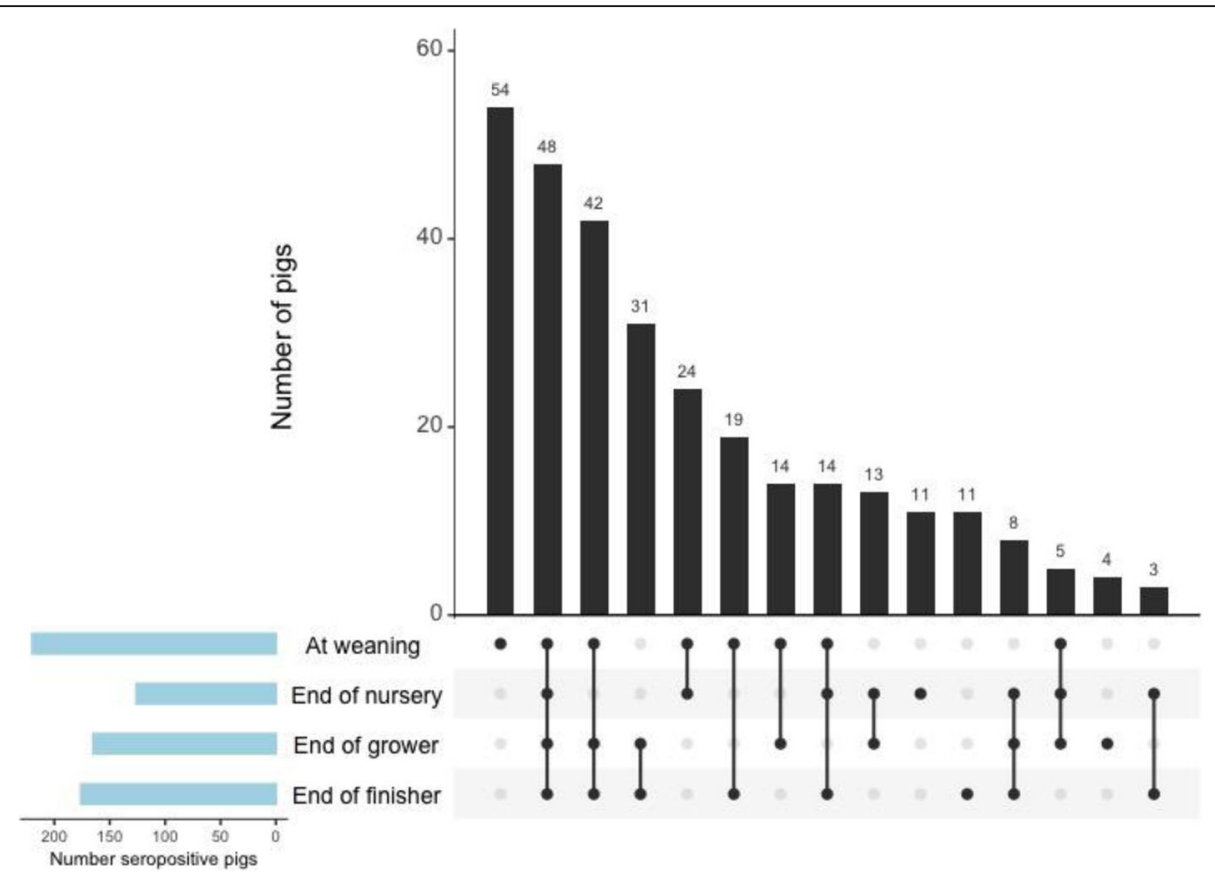

Fig. 4 Combination frequency of pigs that were seropositive for $M$. hyopneumoniae at different stages of production. This figure displays pigs that were tested at 4 visits and were seropositive for Mycoplasma hyopneumoniae (M. hyopneumoniae) at least once throughout production. The data are presented as intersections for each combination of production stages in which pigs were seropositive, with seropositivity represented by dots in the horizontal axis. The number of seropositive pigs per intersection are displayed above the corresponding bar and arranged from the largest intersection to the smallest. Dots are connected by a line if pigs were seropositive at more than 1 production stage. For example, the largest number of pigs were seropositive for $M$. hyopneumoniae only at weaning, followed by pigs that were only seropositive at the end of the finisher stage, etc.

farrowing sources or their out-going groups. Thus, it is largely assumed that increases in antibody responses postweaning were the result of natural infection.

Older pigs were less likely to be seropositive for $M$. hyopneumoniae than younger pigs, and this decreased likelihood for M. hyopneumoniae seropositivity may indicate the vulnerability of weanlings to infection, as antibody responses did not seem to increase significantly with age. This may also indicate the lack of $M$. hyopneumoniae infections in the later production stages. Due to the tendency of $M$. hyopneumoniae to produce chronic infections in the host, the assumption is that after the decline of maternal antibodies, the young pigs mount a slower immune response [22] or that $M$. hyopneumoniae

Table 4 Mixed-effects multi-level logistic regression analysis for Mycoplasma hyopneumoniae

\begin{tabular}{|c|c|c|c|c|}
\hline Parameter & Odds ratio & Standard error & $95 \%$ confidence interval & p-value \\
\hline \multicolumn{5}{|c|}{ IAV seropositivity } \\
\hline No & Referent & & & \\
\hline Yes & 2.5 & 0.62 & $1.5-4.1$ & $<0.001$ \\
\hline \multicolumn{5}{|c|}{ Farrowing source } \\
\hline 5 & Referent & & & \\
\hline 7 & 0.34 & 0.16 & $0.14-0.86$ & 0.022 \\
\hline 8 & 0.08 & 0.04 & $0.03-0.22$ & $<0.001$ \\
\hline Age (weeks) & 0.93 & 0.015 & $0.90-0.96$ & $<0.001$ \\
\hline
\end{tabular}

This table displays the mixed-effects multi-level logistic regression analysis for Mycoplasma hyopneumoniae seropositivity with sow as a random effect in 4 seropositive groups from 3 farrowing sources. Six groups had more than $20 \%$ of pigs test seropositive for $M$. hyopneumoniae at least once from the end of nursery to the end of finisher by ELISA. However, 2 seropositive groups from 1 farrowing source were excluded from the multivariable analysis as sows and pigs were vaccinated for M. hyopneumoniae IAV Influenza A virus

${ }^{a}$ Cohort One: Pigs were born between May and August; Cohort Two: Pigs were born between October and January 


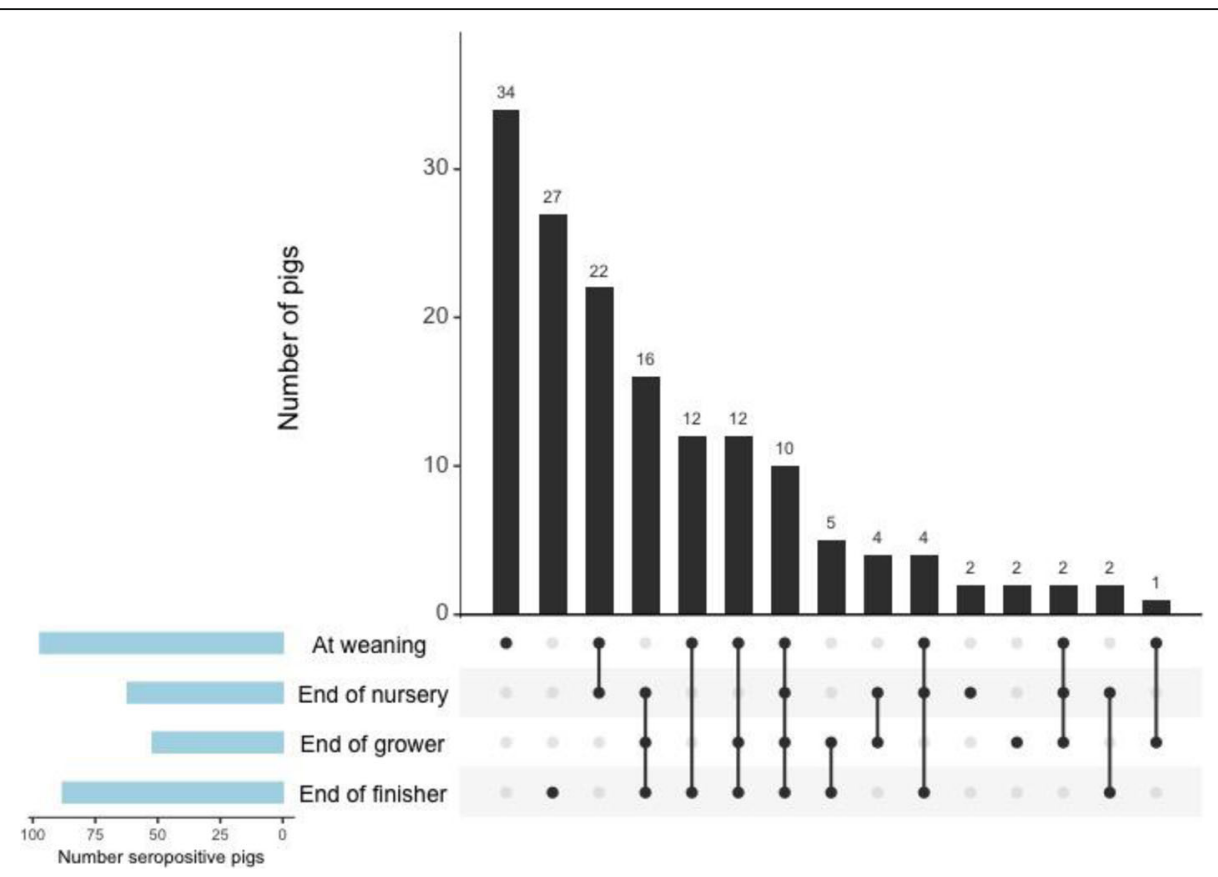

Fig. 5 PRRSV, IAV, and M. hyopneumoniae seropositivity in pigs fed high or low complexity nursery diet. This figure depicts the proportion of seropositivity to porcine reproductive and respiratory syndrome virus (PRRSV), influenza A virus (IAV), and Mycoplasma hyopneumoniae among pigs fed high or low complexity diet in seropositive groups. Note: 2, 9, and 4 groups were classified as seropositive for PRRSV, IAV, and M. hyopneumoniae, respectively. ${ }^{*} \mathrm{p}<0.05$

itself is slower to spread and thus antibody responses appear delayed [23].

The second objective of this study was to determine if infection with one pathogen increases the likelihood for seropositivity to another. It was found that pigs in seropositive groups that were seropositive for IAV were more likely to be seropositive for PRRSV and $M$. hyopneumoniae. Additionally, pigs in seropositive groups that were seropositive for M. hyopneumoniae were more likely to be seropositive for IAV. The present study did not determine if co-infection could produce more severe disease, but these results have been reported in the past [7, 24]. Additionally, while managerial factors, such as pig density and pig flow, would affect the spread of disease on farm, it is possible that infection with one agent would increase susceptibility to other agent(s). This suggests that while controlling for the presence of one pathogen is important, in order to prevent more severe disease, control strategies should be directed towards preventing co-infection. Understanding which pathogens are a threat on a farm-specific basis using techniques such as ELISA may help in reducing the detrimental effects of co-infection.

The third objective of this study was to investigate whether a low complexity nursery diet with a higher amount of fibre provided by corn and soybean was associated with antibody responses to PRRSV, IAV, and $M$. hyopneumoniae. Pigs fed a low complexity nursery diet were more likely to be seropositive for PRRSV; however, there was no significant association between nursery diet and IAV or M. hyopneumoniae seropositivity. This experimental low complexity diet has also been previously found to have no effect on antibody responses to Salmonella [19]. These results may suggest that the low complexity diet increased the susceptibility of pigs to PRRS virus but had no effect on susceptibility to IAV, M. hyopneumoniae, or Salmonella. Alternatively, these results may indicate that the $\mathrm{LC}$ diet elevated the immune response to PRRSV while having no effect on the immune response to IAV, M. hyopneumoniae, and Salmonella. From a production standpoint, the lack of association between antibody responses to IAV and $M$. hyopneumoniae and feeding the low complexity nursery diet is promising, as it may encourage the implementation of these cost-saving diets with no adverse effects on herd health. However, the results in this study should be interpreted with caution and need to be examined more thoroughly using control challenge studies. Further investigation into the effects of nursery diet complexity on antibody responses to other notable porcine pathogens may help shed more light on the effects of diet on immune development. Other branches of the immune system, such as cell-mediated immune responses, should also be examined. Additionally, the possible effect of diet complexity on the digestive health on the animals 
requires further scrutiny to ensure adverse effects on digestion do not occur as a result of feeding lower complexity nursery diets.

While seropositivity at the pig level was relatively high, a proportion of pigs remained seronegative throughout all stages of production. This indicates either that these pigs were never exposed to the infectious agents; that animals were exposed but the pathogens were unable to bypass the innate immune system in order to establish infection and activate the adaptive immune system; that an immune response was generated but was not robust enough to be read as seropositive by the ELISA kits; or that pigs had not yet seroconverted at the time of sample collection. However, there may have also been some variation in results based on the ELISA kits used for antibody detection. The IDEXX ELISA kits have been found to have 100\% sensitivity and 99.9\% specificity for PRRSV [25]; 86 and $89 \%$ for IAV [26]; and relatively low sensitivity (63\%) but high specificity (100\%) for M. hyopneumoniae [22]. However, as noted by Erlandson et al. [18], the low sensitivity of the $M$. hyopneumoniae test is likely due to the nature of the infectious agent and the slow immune response produced by $M$. hyopneumoniae rather than the ability of the ELISA kits to identify seropositive pigs. The low sensitivity could also be due to the slow transmission of M. hyopneumoniae, which would also delay the seroconversion [23]. This seems to suggest that the pathogen is still present throughout production but the propagation between animals is slow or the immune response itself is delayed. This low sensitivity may have increased the chance of false negatives in this study but considering a pig "seropositive" if it tested seropositive at least once over the course of production likely worked to counteract this issue. Further, the ELISA kits used in this study could only detect IgG antibodies, which may have resulted in more recent infections at one specific sampling occasion being left undetected (false negative). However, these infections could eventually be detected over the next sampling time points.

The ELISA kits used in this study were unable to differentiate between antibody responses to natural infections and vaccination. However, because only one farrowing source was vaccinated for M. hyopneumoniae and the corresponding groups were not included in the analyses, the seropositivity observed in the high seropositivity groups can be largely assumed to be from maternal antibodies in the early stages of production and natural infection later in life. These results may help to encourage vaccination in post-weaning pigs, when the interaction between maternal antibodies and vaccine antigens is minimized [10].

\section{Conclusion}

Understanding periods of vulnerability on farm is important in order to develop site-specific methods of disease prevention and control. Monitoring frequently for changes in the seroprevalence of pathogens on swine farms may help to confer broader protection and improve animal health and welfare. Finally, while further research is needed to investigate the association between low complexity nursery diets and other important health factors, such as other branches of the immune system and the effects on digestive health, this study suggests that low complexity nursery diets, which offer costsaving incentives, may be beneficial on farms with low disease pressures.

\section{Methods}

\section{Farrowing source and pig selection}

The farrowing source and pig selection have been described previously $[19,27]$. Briefly, fourteen groups of 54-60 pigs from a convenience sample originating from eight farrowing sources in Southwestern Ontario were selected. Two cohorts (Cohort One and Two) were included in the study from six of the eight farrowing sources, while the other two included only one cohort (Cohort One). Pigs in Cohort One were born between May and August, while pigs in Cohort Two were born between October and January. All sources but one utilized off-site nursery and finishing, while the other was farrow-to-finish for Cohort One and off-site finisher for Cohort Two.

\section{Diet}

Pigs in each group were divided equally to receive either a standard animal-protein based (high complexity, HC) diet $(\mathrm{n} 1=27-30)$ or an experimental plant (soybean and corn)- protein based, (low complexity, LC) diet (n2= 27-30) during the nursery phase. Both diets were formulated with similar nutrient levels but different ingredient composition. The high-complexity diet contained whey, fishmeal, and soy protein concentrate, while in the lowcomplexity diet the majority of the protein was primarily sourced from corn and soybean meal [17, 28]. A detailed breakdown of ingredient composition and feeding schedule has been published previously [14]. The diets were administered in three phases and were available ad libitum, with phases I, II, and III being fed for an average of 9, 15, and 14 days, respectively. At all other stages, all pigs were fed common grower and finisher diets according to the practices of the individual farms. Pigs were tagged to ensure both that they received their intended diet and that samples could be taken at multiple visits.

\section{Questionnaire}

A questionnaire was used to obtain information regarding farm management practices (Additional File 1). 


\section{Sample collection}

Blood samples were collected from all pigs at weaning and at the end of the nursery, grower, and finisher stages in all 14 groups except for one, where samples were not collected at the end of the finisher stage. Samples were collected between May 2014 and June 2016. Average ages of pigs at each sampling point were $26,61,106$, and 145 days at weaning, the end of nursery, end of grower, and end of finisher, respectively. Blood samples were collected from either the jugular vein or suborbital sinus and centrifuged at $1500 \mathrm{xg}$ for $20 \mathrm{~min}$.

\section{Enzyme-linked immunosorbent assay (ELISA)}

Sera were analyzed for the presence of PRRSV, IAV, and $M$. hyopneumoniae antibodies using three commercially available ELISA Kits (Porcine Reproductive and Respiratory Syndrome Virus Antibody Test Kit; Swine Influenza Virus Antibody Test Kit; Mycoplasma Hyopneumoniae Antibody Test Kit; IDEXX Laboratories, Inc., Westbrook, Maine, USA) as per the manufacturer's instructions. The sensitivities and specificities for each ELISA were: 100 and $99.9 \%$ for PRRSV; 86 and $89 \%$ for IAV; and 63 and 100\% for M. hyopneumoniae. A pig was considered seropositive for a specific pathogen if it was seropositive at least once from the end of nursery to the end of the finisher stage for that pathogen. However, in order to increase the test specificity at the group level, a group was classified as positive for a pathogen if at least $20 \%$ of the pigs in the group were seropositive for that pathogen at least once from the end of nursery to the end of the finisher stage.

A sample-to-positive $(S / P)$ ratio for PRRSV antibodies was calculated as follows:

$$
\mathrm{S} / \mathrm{P}=\frac{\text { Sample absorbance }(650)-\text { Mean }_{\text {negative control }}}{\text { Mean }_{\text {positive control }}-\text { Mean }_{\text {negative control }}}
$$

A pig was considered seropositive for PRRSV if the $S$ / $P$ ratio was $\geq 0.4$.

A sample-to-negative $(S / N)$ ratio for IAV was calculated as follows:

$$
\mathrm{S} / \mathrm{N}=\frac{\text { Sample absorbance }(650)}{\text { Mean }_{\text {negative control }}} \quad \text { (controlcontrol) }
$$

A pig was considered seropositive for IAV if the $S / N$ ratio was $<0.6$.

A $S / P$ ratio for $M$. hyopneumoniae was calculated as follows:

$$
S / P=\frac{\text { Sample absorbance }(650)-\text { Mean }_{\text {negative control }}}{\text { Mean }_{\text {positive control }}-\text { Mean }_{\text {negative control }}}
$$

A pig was considered seropositive for M. hyopneumoniae if the S/P ratio was $>0.4$.

\section{Data analysis}

Data were cleaned in Excel (Microsoft 2016, Redmond, Washington, USA) and transferred to Stata (Stata/MP-13 StataCorp, College Station, Texas, USA) for analysis. Samples from weaning to the end of the finisher stage were included in the data analysis from only those pigs within seropositive groups. A mixedeffects multi-level logistic regression method with farrowing source and sow as random effects to account for clustering was used to compare IAV and M. hyopneumoniae seropositivity in pigs at different stages of production. For PRRSV, only sow was included as a random effect because only two groups were seropositive and included in the data analysis. Two M. hyopneumoniae seropositive groups from farrowing source \#1 were excluded from data analysis as sows and outgoing pigs were vaccinated for $M$. hyopneumoniae. The independent variables considered as fixed effects were nursery diet $(\mathrm{HC} / \mathrm{LC})$, cohort (i.e. Cohort One or summer: pigs were born between May and August; Cohort Two or winter: pigs were born between October and January), age, production stage (end of nursery/end of grower/end of finisher), and seropositivity to other pathogens of interest for the present study (yes/no). While groups were classified as seropositive if at least $20 \%$ of pigs in that group were seropositive at least once from the end of nursery to the end of the finisher stage, statistical analyses were performed at the pig level in those seropositive groups, including samples at weaning to determine changes in seropositivity over the course of production. Univariable analysis for the association between the independent variables and pig seropositivity to each pathogen was first evaluated by a single logistic regression method, and variables with a $p<0.2$ were considered for inclusion in the multivariable analysis. Models were then built using a manual forward stepwise approach and variables were included in the final models if $p<0.05$. The normal quantiles plots were created to evaluate the normality assumption for each model. Also, in order to examine homoscedasticity of the best linear unbiased predictors (BLUPS) the BLUPS were plotted against the predicted log odds of the outcome in each model. The Pearson residuals were generated and used to identify outliers.

\section{Supplementary Information}

The online version contains supplementary material available at https://doi. org/10.1186/s12917-021-02756-6.

Additional file 1. Questionnaire. This questionnaire was developed and used to collect information about management practices in place on participating farms. 


\section{Abbreviations}

ELISA: Enzyme-linked immunosorbent assay; HC: High complexity; IAV: Influenza A virus; LC: Low complexity; PRRSV: Porcine reproductive and respiratory syndrome virus; S/N: Sample-to-negative; S/P: Sample-to-positive

\section{Acknowledgements}

The authors would like to thank Corinne H. Schut, Heather Reinhardt, Margaret H. Ainslie-Garcia, Emily R. Arndt, Jane E. Newman, Pauldeep S. Virk, Bailey M. Fuller, and Dr. Jutta Hammermüller for their assistance in sample collection and laboratory works as well as pork producers who participated in this study.

\section{Authors' contributions}

$A F, B N L$, and RMF designed the study. ER performed ELISA. ER and AF conducted data analysis. All authors contributed to drafting and revising of the manuscript. All authors read and approved the final manuscript.

\section{Funding}

Funding was provided by the Natural Sciences and Engineering Research Council of Canada Collaborative Research and Development Grant (project number 488429-15), the Ontario Ministry of Agriculture, Food and Rural Affairs (project number UofG2013-1472), Swine Innovation Porc (project number 1239e), and Ontario Pork (project number 15/015]. Funding sources had no role in the study design, sample collection, data analysis, and in writing the manuscript.

\section{Availability of data and materials}

The data used and analyzed during the current study are available from the corresponding author upon request.

\section{Ethics approval and consent to participate}

Animal use was approved by the University of Guelph Animal Care Committee (Animal Utilization Protocol \# 3124) and follows Canadian Council of Animal Care guidelines (CCAC, 2009). Informed verbal consent was acquired from producers as approved by the ethics committee.

\section{Consent for publication}

Not applicable.

\section{Competing interests}

The authors declare that they have no competing interests.

\section{Received: 13 March 2020 Accepted: 11 January 2021}

\section{Published online: 17 February 2021}

\section{References}

1. Haden C, Painter T, Fangman T, Holtkamp D. Assessing production parameters and economic impact of swine influenza, PRRS and Mycoplasma hyopneumoniae on finishing pigs in a large production system. In: AASV Annual Meeting; 2012. [cited 2018 Apr 9]. p. 75-6. Available from: https:// vetmed.iastate.edu/sites/default/files/vdpam/Cara Haden AASV Abstract.pdf.

2. Wilson MR, Takov R, Friendship RM, Martin SW, McMillan I, Hacker RR, et al. Prevalence of respiratory diseases and their association with growth rate and space in randomly selected swine herds. Can J Vet Res. 1986;50(2):20916.

3. USDA. Swine 2012 Part II: Reference of Swine Health and Health Management in the United States. Fort Collins, Colo.; 2012.

4. Bin L, Luping D, Bing S, Zhengyu Y, Maojun L, Zhixin F, et al. Ttranscription analysis of the porcine alveolar macrophage response to Mycoplasma hyopneumoniae. Chang Y-F, editor. PLoS One. 2014; [cited 2018 Apr 8];9(8): e101968. Available from: https://journals-scholarsportal-info.subzero.lib. uoguelph.ca/pdf/19326203/v09i0008/nfp_taotpamrtmh.xml.

5. Kothalawala H, Toussaint MJM, Gruys E. An overview of swine influenza. Vet Q. 2006;28(2):45-53 [cited 2018 May 17]. Available from: https://www. tandfonline.com/doi/pdf/10.1080/01652176.2006.9695207? needAccess=true.

6. Huang C, Zhang Q, Feng W-H. Regulation and evasion of antiviral immune responses by porcine reproductive and respiratory syndrome virus. Virus Res. 2015;202:101-11 [cited 2018 Apr 5]. Available from: https://ac-els-cdncom.subzero.lib.uoguelph.ca/S016817021400519X/1-s2.0-S01681702140051 9X-main.pdf?_tid=bf5dde29-a82a-48f7-8506-c98a48cb43c0\&acdnat=1522 905359_cf109a747ebed476731611c08e599072.
7. Thacker EL, Thacker BJ, Janke BH. Interaction between Mycoplasma hyopneumoniae and swine influenza virus. J Clin Microbiol. 2001:39(7):252530 [cited 2019 Sep 7]. Available from: https://www.ncbi.nlm.nih.gov/pmc/ articles/PMC88180/pdf/jm002525.pdf.

8. Thanawongnuwech R, Thacker B, Halbur P, Thacker EL. Increased production of proinflammatory cytokines following infection with porcine reproductive and respiratory syndrome virus and Mycoplasma hyopneumoniae. Clin Diagn Lab Immunol. 2004;11(5):901-8 [cited 2018 Apr 11]. Available from: http:// cvi.asm.org/content/11/5/901.full.pdf.

9. Risco D, Cuesta JM, Fernández-Llario P, Salguero FJ, Gonçalves P, GarcíaJiménez $W L$, et al. Pathological observations of porcine respiratory disease complex (PRDC) in the wild boar (Sus scrofa). Eur J Wildl Res. 2015;61(5): 669-679 [cited 2018 Apr 8]. Available from: https://link-springer-com. subzero.lib.uoguelph.ca/content/pdf/10.1007\%2Fs10344-015-0937-1.pdf

10. Chase CCL, Lunney JK. Immune System. In: Diseases of Swine [Internet] 10th ed. Chichester: Wiley-Blackwell; 2012. [cited 2019 Jun 4]. Available from: http://web.b.ebscohost.com.subzero.lib.uoguelph.ca/ehost/ ebookviewer/ebook/bmxIYmtfXzQzNzY4MF9fQU41?sid=c56f0a5c-76 d0-4235-8b19-5af7925526fe@sessionmgr103\&vid=0\&format=EK\&lpid= navpoint-115\&rid $=0$

11. Poljak Z, Dewey CE, Martin SW, Christensen J, Carman S, Friendship RM Prevalence of and risk factors for influenza in southern Ontario swine herds in 2001 and 2003. Can J Vet Res. 2008;72(1):7-17 Available from: http:// www.ncbi.nlm.nih.gov/pubmed/18214156.

12. Levis DG, Baker RB. Biosecurity of pigs and farm security. 2015 [cited 2018 Apr 5]. Available from: http://porkgateway.org/wp-content/uploads/2015/ 07/biosecurity-of-pigs-and-farm-security1.pdf

13. National Research Council. Nutrient Requirements of Swine, 10th ed. 1998 [cited 2020 Jun 12]. Available from: http://www.nap.edu

14. Carr J. The maintenance of health. In: Whittemore's Science and Practice of Pig Production; 2007. p. 263-316

15. Phase Feeding Pigs | Purina Animal Nutrition [Internet]. [cited 2019 Nov 1]. Available from: https://www.purinamills.com/swine-feed/education/detail/ phase-feeding-pigs

16. Hazzledine M, Whittemore C. Diet formulation. In: Whittemore's science and practice of pig production [Internet]. Oxford: Blackwell Publishing Ltd; 2006. p. 438-71. Available from: https://linkinghub.elsevier.com/retrieve/pii/B97804 09325256500177.

17. Skinner LD, Levesque CL, Wey D, Rudar M, Zhu J, Hooda S, et al. Impact of nursery feeding program on subsequent growth performance, carcass quality, meat quality, and physical and chemical body composition of growing-finishing pigs. J Anim Sci. 2014;92:1044-54 [cited 2018 Oct 31]. Available from: https://academic.oup.com/jas/article-abstract/92/3/1044/4 702219.

18. Che L, Zhan L, Fang Z, Lin Y, Yan T, Wu D. Effects of dietary protein sources on growth performance and immune response of weanling pigs; 2012 [cited 2019 Jun 27]; Available from. https://doi.org/10.1016/j.livsci.2012.04.019.

19. Schut CH, Farzan A, Ainslie-Garcia MH, Friendship RM, Lillie BN. Antibody responses to Salmonella in pigs from weaning up to marketing and presence of Salmonella at slaughter. Foodborne Pathog Dis. 2019;16(3):18794 [cited 2019 Jan 7]. Available from: www.liebertpub.com.

20. Klobasa F, Habe F, Werhahn E, Butler JE. Changes in the concentrations of serum $\lg G, \lg A$ and $\lg M$ of sows throughout the reproductive cycle. Vet Immunol Immunopathol. 1985;10(4):341-53.

21. Werhahn E, Klobasa F, Butler JE. Investigation of some factors which influence the absorption of IgG by the neonatal piglet. Vet Immunol Immunopathol. 1981;2(1):35-51 [cited 2019 Jun 6]. Available from: https:// journals-scholarsportal-info.subzero.lib.uoguelph.ca/pdf/01652427/v02 i0001/35_iosfwioibtnp.xml.

22. Erlandson KR, Evans RB, Thacker BJ, Wegner MW, Thacker EL. Evaluation of three serum antibody enzyme-linked immunosorbent assays for Mycoplasma hyopneumoniae. J Swine Health Prod. 2005;13(4):198-203 [cited 2019 Jan 28]. Available from: http://www.aasv.org/shap.html.

23. Meyns T, Maes D, Dewulf J, Vicca J, Haesebrouck F, De KA. Quantification of the spread of Mycoplasma hyopneumoniae in nursery pigs using transmission experiments. Prev Vet Med. 2004;66(1-4):265-75 [cited 2020 Jun 19]. Available from: www.elsevier.com/locate/prevetmed.

24. Thacker EL, Halbur PG, Ross RF, Thanawongnuwech R, Thacker BJ. Mycoplasma hyopneumoniae potentiation of porcine reproductive and respiratory syndrome virus-induced pneumonia. J Clin Microbiol. 1999;37(3): 620-7 [cited 2019 Sep 7]. Available from: http://jcm.asm.org/. 
25. Seo BJ, Kim H, Cho HS, Park BY, II KW. Evaluation of two commercial PRRSV antibody ELISA kits with samples of known status and singleton reactors. J Vet Med Sci. 2016;78(1):133-8.

26. Tse M, Kim M, Chan C-H, Ho P-L, Ma S-K, Guan Y, et al. Evaluation of Three Commercially Available Influenza A Type-Specific Blocking Enzyme-Linked Immunosorbent Assays for Seroepidemiological Studies of Influenza A Virus Infection in Pigs. 2012 [cited 2019 Sep 22]; Available from: http://www.offlu. net/fileadmin/home/en/meeting

27. Ainslie-Garcia MH, Farzan A, Jafarikia M, Lillie BN. Single nucleotide variants in innate immune genes associated with Salmonella shedding and colonization in swine on commercial farms. Vet Microbiol. 2018;219:171-177 [cited 2018 Sep 18]. Available from: https://doi.org/10.1016/j.vetmic.2018.04. 017.

28. Reinhardt H, Shoveller AK, Farzan A, McBride B, Huber L-A, CFM d L. Effect of nursery feeding program on serum haptoglobin, growth performance, and carcass characteristics of pigs reared on commercial farms. Can J Vet Res. 2019;83(4):255-60 [cited 2020 Jun 3]. Available from: http://repositorio. unan.edu.ni/2986/1/5624.pdf.

\section{Publisher's Note}

Springer Nature remains neutral with regard to jurisdictional claims in published maps and institutional affiliations.

Ready to submit your research? Choose BMC and benefit from:

- fast, convenient online submission

- thorough peer review by experienced researchers in your field

- rapid publication on acceptance

- support for research data, including large and complex data types

- gold Open Access which fosters wider collaboration and increased citations

- maximum visibility for your research: over $100 \mathrm{M}$ website views per year

At BMC, research is always in progress.

Learn more biomedcentral.com/submissions 